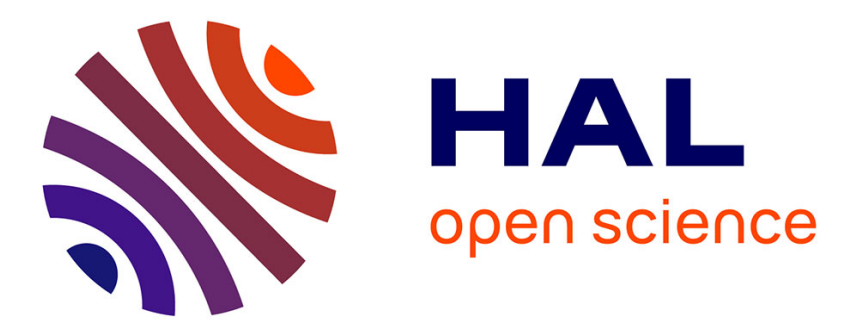

\title{
Complexity Management in Production Systems: Approach for Supporting Problem Solving Through Holistic Structural Consideration
}

Samuel Horler, Ralph Riedel, Egon Müller

\section{- To cite this version:}

Samuel Horler, Ralph Riedel, Egon Müller. Complexity Management in Production Systems: Approach for Supporting Problem Solving Through Holistic Structural Consideration. IFIP International Conference on Advances in Production Management Systems (APMS), Sep 2019, Austin, TX, United States. pp.414-422, 10.1007/978-3-030-30000-5_52 . hal-02419265

\section{HAL Id: hal-02419265 \\ https://hal.inria.fr/hal-02419265}

Submitted on 19 Dec 2019

HAL is a multi-disciplinary open access archive for the deposit and dissemination of scientific research documents, whether they are published or not. The documents may come from teaching and research institutions in France or abroad, or from public or private research centers.
L'archive ouverte pluridisciplinaire HAL, est destinée au dépôt et à la diffusion de documents scientifiques de niveau recherche, publiés ou non, émanant des établissements d'enseignement et de recherche français ou étrangers, des laboratoires publics ou privés.

\section{(c)(1)}

Distributed under a Creative Commons Attribution| 4.0 International License 


\title{
Complexity Management in Production Systems: Approach for supporting problem solving through holistic structural consideration
}

\author{
Samuel Horler, Ralph Riedel, and Egon Müller \\ Chemnitz University of Technology, 09107 Chemnitz, Germany \\ \{samuel.horler, ralph.riedel, egon.mueller\}@mb.tu-chemnitz.de
}

\begin{abstract}
Both external and internal influences affect the way production systems are planned and operated. Long-standing trends combined with topics such as digitization and artificial intelligence are increasing the complexity of tackling problems in production systems. Along with this, there is the ever increasing risk of planning errors and the loss of long-term competitiveness. This paper presents an innovative approach that supports problem-solving processes in the planning and operation of production systems. For this purpose, qualitative structural modeling and analysis of problem situations are applied. At its core, the article focuses on a framework, which forms the basis for the modeling of problem situations, their analysis and the organizational and technical integration of the method. Furthermore, with the concept of building block based domain-relation models, a possibility is presented with which the structure of problem situations can be modeled and analyzed.
\end{abstract}

Keywords: Complexity Management, Modeling, Production Management, Production Systems, Collaborative Tools.

\section{$1 \quad$ Introduction and Research Motivation}

Manufacturing companies have long been exposed to global trends that have a significant impact on the way they create value. In addition to some temporarily relevant trends, the most significant change drivers in the recent past have been identified by the continuing globalization, the high volatility and dynamics of the markets as well as a change in values towards individualization and sustainability [1]. Thereby, the digital transformation of the industry represents an approach to enable production to meet these challenges [2]. This results in numerous new requirements, which cannot be covered by classical planning procedures [3].

As a consequence of these influences, both the exogenous and the endogenous complexity increase, which affect the planning as well as operation of the production system. In general, three main types of complexity can be distinguished [4]:

- Environmental complexity - uncontrollable trends from market, customers etc.

- Value/service complexity - diversity and amount of product variants provided 
- Internal complexity - variety of elements and processes in the system itself

Figure 1 illustrates the main reasons for increasing complexity in production systems, divided in human, technical and organizational aspects. These influences arise from previous research as the essence of an extensive literature analysis of the past years as well as from experiences from the scientific work and planning practice at Chemnitz University of Technology.

\begin{tabular}{|c|c|c|c|}
\hline & Human & Machine & Organization \\
\hline \multirow{2}{*}{ ن } & Production on demand & Disrupting technologies & Ad hoc collaboration networks \\
\hline & Buyer's market & High reaction speeds & Service-orientation \\
\hline \multirow{3}{*}{ ¿ } & Variety of products/processes & Complicated product structure & Multiple, changing projects \\
\hline & Interdisciplinary collaboration & High production accuracy & Changing responsibilities \\
\hline & Decentralized knowledge & & Production flexibility \\
\hline \multirow{4}{*}{ 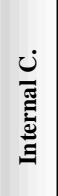 } & Process intransparency & Technological innovations & High amount of tools/methods \\
\hline & Data based decisions & M2M/M2X Communication & Vertical/horizontal integration \\
\hline & Advanced HMI & Artificial intelligence & Time pressure \\
\hline & Individual problem-solving & CPS self-organization & \\
\hline
\end{tabular}

Fig. 1. Reasons for higher complexity in planning and operation of production systems

In production systems, humans act at various levels and situations as problem solvers in planning and operating. Their activities, however, are becoming increasingly difficult to carry out, since those are to be performed in complex situations - problem areas and effective ranges cannot be sufficiently limited. As a consequence, humans are overwhelmed in assessing prevailing problems and identifying solution providers/hurdles. As a result, typical challenges consist of assessing the scope of the problem, participating domains/persons, critical system elements, interactions between elements etc.

Since the behavior and thus the output of systems result from its structural composition, a structural consideration of production systems and problem situations is considered to be beneficial. From this reasoning, the following overall research question was derived: How can the prevailing structure of production systems in complex problem situations be systematized and analyzed in order to support problem-solving in factory planning and operation through the specific reduction of complexity and to enable managing the complexity in the object area?

As a research method, the Design Science Research (DSR) was chosen, which aims to develop human created artifacts while looping relevance and rigor cycles. So, the potential gap between theory and practice can be reduced, while developing artifacts, which are subjected to repeated evaluation [5]. This article concretizes the stated problem and presents an approach to address the research question by suggesting a method for supporting problem-solving processes in production systems through structural consideration. 


\section{State of the Art of Complexity Management}

There is a wide variety of contributions from various disciplines on dealing with complexity. Referring to the DSR rigor cycle, a comprehensive literature analysis was conducted in order to examine the knowledge base for applicable foundations and methodologies.

In Science, there are two mostly different approaches in the field of complexity research. On the one hand there are analytic-reductionist approaches, on the other side systemic-evolutionary ones. In general, the focus in various areas is on developing suitable approaches, concepts and strategies to deal with complexity. This is summarized under the term complexity management. Historically, complexity science originated from scientific findings in Cybernetics [6] as well as classical Systems Science [7, 8] in 1960s. Towards the end of the 1980s research was decisively driven by organizational and management research. Driven by Pioneer Beer [9], the St. Gallen School picked up on these ideas and pushed research in management cybernetics [10-12]. Fricker presents a variety of enterprise-oriented traditional approaches to complexity management [13]. Particularly noteworthy are the works of Malik on management cybernetics [14]. The evolutionary approaches outlined here, which are based on Beer's Viable Systems Model, formed the basis for many other research activities.

With regard to more recent research, especially matrix-based approaches should be emphasized, which build on the analytical complexity management and aim at the modeling and analysis of existing structures. In the context of product development, Lindemann aims to use multi-dimensional matrices to reduce the complexity of projects and thus improve the project results [15]. Building on this, Kreimeyer explored how to extend this approach through metrics and thus improve the analysis capability of multidimensional matrices [16]. Petraus took up those approaches and transfered them into factory planning projects by developing a communication analysis methodology based on the project structure and organization [17].

The review of the state of science revealed (DSR rigor cycle) that so far no methods exist that could meet the objectives set out above. Nevertheless, selected existing approaches should be taken up, transferred or further developed.

\section{Problem Solving in Planning and Operating of Production Systems}

According to Nyhuis [18], a production system is defined as a socio-technical system that transforms input into output by means of value-adding and associated processes. Schmigalla [19] characterizes such a system by a certain amount of elements, processes that take place over these elements as well as a structure which is formed by the resulting relation between the elements. The activities of factory planning and factory operation are closely linked. The planning shapes the potential for the value creation process in the factory. Operation activities are responsible for the productive usage of those potentials. As a consequence, it can be stated that in factory operation control processes and in factory planning design processes take priority [20]. The processes involved in 
these functions are individual and collective problem-solving processes. These processes are determined by characteristics of the task, the situation and the problem-solving persons [20]. Generally, individual and collective problem solving in a specific organizational context is embedded in a larger context, which decisively influences certain situational characteristics.

In addition to the object area of production, also the planning and control of production can be understood as a system with elements, relationships, which is embedded in an environment. Thus both the object and the methods can be described as complex due to the high number, variability, diversity of their components and the processes taking place in them, as well as the associated uncertainty and limited predictability with regard to system behavior. This means that existing problem-solving processes must deal with complexity - as a result, involved persons are confronted with complex problem and decision situations. With reference to Ashby's law of requisite variety, complexity itself cannot be considered negative; it is even mandatory in systems to survive in complex environmental situations [21]. So complexity is not a problem in production systems per se. Rather, it is the inability of the humans to deal with this complexity, which leads to serious consequences.

In complex situations, knowledge about the structural consideration of problem and solution elements can provide valuable information to facilitate the solution generation process. Nevertheless, in most complex problem situations, the underlying dependencies are unknown, resulting in a lack of structural knowledge. Riedel [20] provides an generic operative model for problem solving in planning and control in factory planning and operation. Based on this, potential fields of application can be derived, in which structural consideration comes into play:

- Analyze and evaluate initial situations and narrow down of goals

- Creation or completion of procedure plans, which fits to structural condition

- Estimation of effect expectations

- Benefits in terms of knowledge activation and isolation of problem scope

In this article, the following illustrative example of a complex problem in a production system is used: Due to expected higher volatility, a project was initiated to increase production flexibility through the possibilities of digitization. Therefore, various subprojects were started in the production areas, which are confronted with a high level of complexity, due to the large number of simultaneous activities, goals and personal responsibilities. Without adequate complexity management, planning errors, uncoordinated results and high costs are at risk.

\section{$4 \quad$ Approach for a Complexity Management based on Structural Consideration of Problem Situations}

\subsection{Framework and Concept}

Based on the previous research, solution approaches for complexity management were developed. Particular consideration was given to preparatory work on the model-based 
presentation of systems, approaches from evolutionary management cybernetics as well as analytical approaches based on matrices and participatory design. The framework shown in Figure 2 visualizes the overall proposed concept.

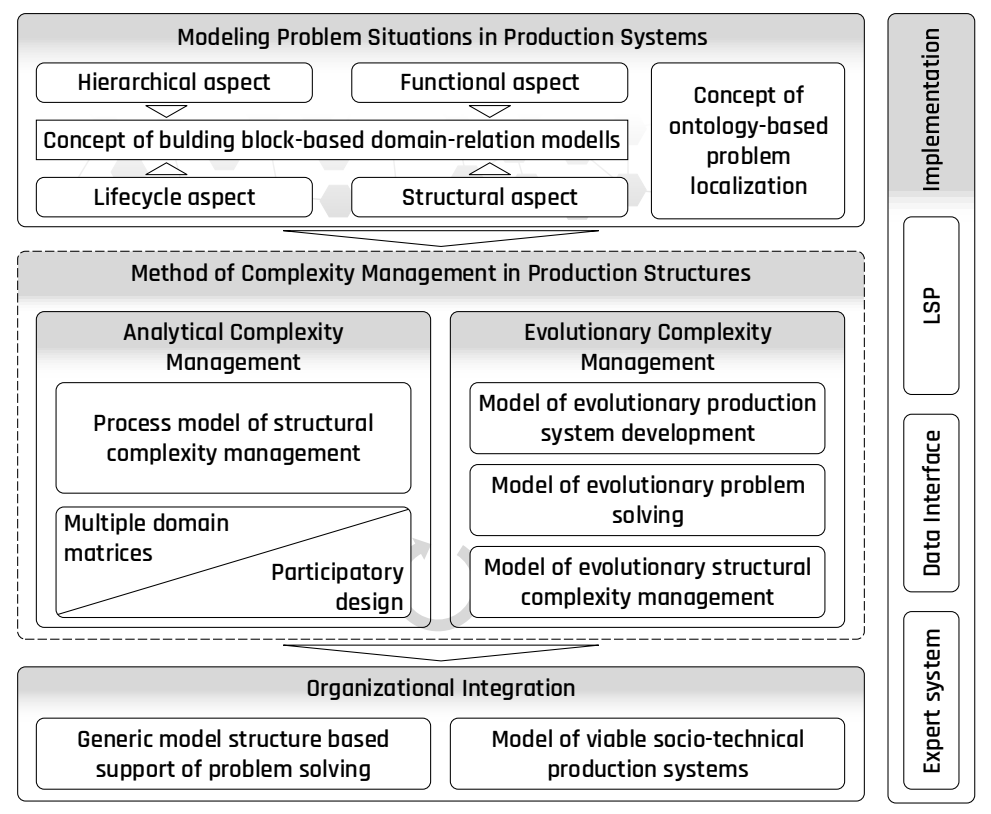

Fig. 2. Framework for complexity management in production structures

The framework for complexity management in complex problem situations is based on the idea of socio-technical systems where humans, technology and organization work together to fulfil the primary tasks. The upper section of the framework (organizational aspect) focuses on the foundation of complexity management by providing a general modeling approach. The middle section (human aspect) provides a methodical concept for dealing with the complex situations. Therefore, a clear distinction was made between analytical and evolutionary handling of complexity. The lower section and the bar handle the integration of the whole concept both organizationally and technically. Two main concepts will be presented below in a compact way.

\subsection{Concept of Modeling Problem Situations}

According to Ropohl [22], to fully describe a system, the three views 'Hierarchy', 'Function' and 'Structure' are essential. Based on these considerations, a concept was developed, which uses building blocks based on domain-relation models (origin: graph theory). In this case a domain is defined as the sum of systems entities of a kind. Transferred to problem situations, domains can be technical, organizational or human aspects such as machines, logistics, workers, objectives, customers, documents, qualifications 
etc. With domains and specified relations between the domains one is able to model problem situations in a qualitative manner.

With the instrument of Multi Domain Matrices (MDM), a problem specific selection of domains and relations can be modeled, where each domain represents a row and a column in the matrix $[15,23]$. That opens up the possibility to not only create intradomain linkages but also inter-domain linkages between elements of different domains. The aim is to enrich certain areas of the MDM with previously hidden content to provide additional knowledge. Thereby already in established algorithms can be used to calculate indirect relations, use metrics or find potential areas of interest.

Referring to the illustrative example, Figure 3 demonstrates a simple MDM with four domains. The chosen relations between the domains are shown in the meta-model, which already merges the necessary constellation of a problem situation. In this situation, the concept could be used to create an aggregated view of this system showing mutual impact between people based on their planning on production units and their consideration of flexibility enables. Such newly created links could help gaining transparency and could be used for decision-making processes.

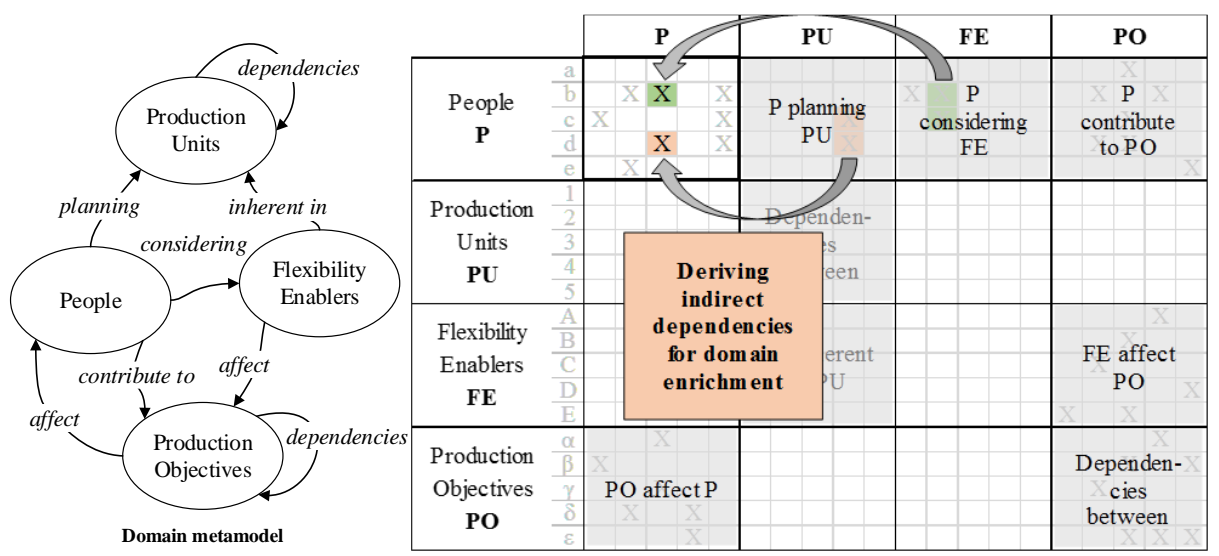

Fig. 3. Structural modeling of complex problem situations using MDM (simplified)

\subsection{Method of Complexity Management in Production Structures}

Consisting of two concepts, the method combines both analytical and evolutionary complexity management. This paper focuses on the analytical concept, which is illustrated in Figure 4. The procedure builds on the preliminary work of Lindemann [15] and was extended and adapted to the current research.

Based on an event or problem in the planning or operation, the overall considered system has to be narrowed down to its relevant components. Therefore, the authors suggest a systems set-up using participatory design methods in order to model desirable future systems states in combination with semantic technologies (e.g. ontologies) to isolate relevant domains. During the following systems definition, the results are transferred into a MDM, covering all necessary facets to get a comprehensive situation 
model. Typical tasks are the determination of domain and relation, the fixation of granularity of consideration and the analysis of the problem scope.

Once the framework of the MDM has been built, the data retrieval of the individual domain must be triggered. Both manual (e.g. interviews) and automated (e.g. information systems) methods can be used. Afterwards, it is possible to narrow down the situation under consideration. After the already indicated calculation of indirect dependencies has been carried out, the structural analysis tries to gain added value from this new constellation of the structure. Once a satisfactory structural analysis has been performed, the results obtained can be used in further problem-solving activities, that lastly lead to better solutions in the real production system.

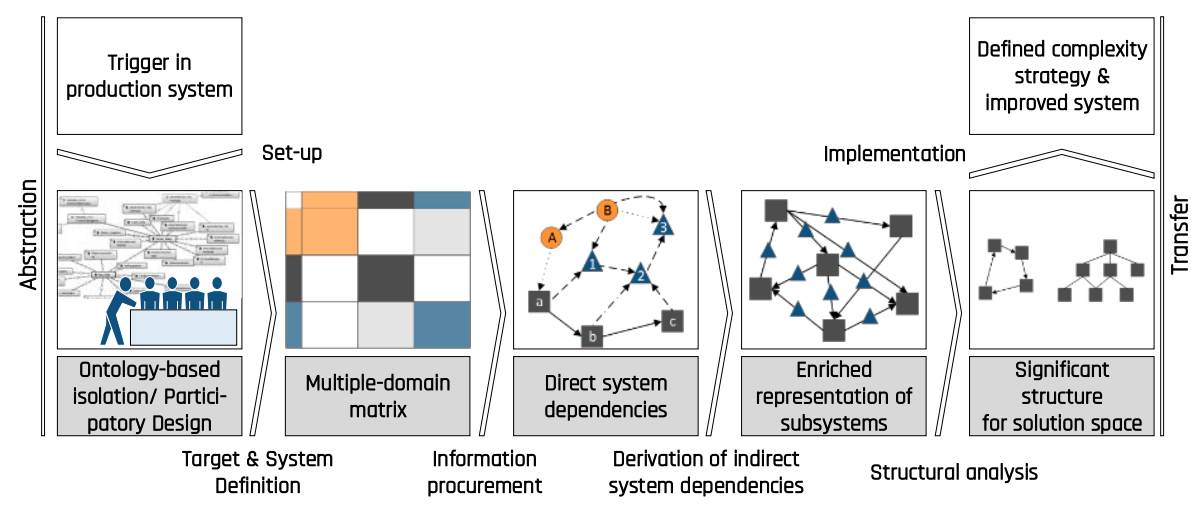

Fig. 4. Analytical problem solving with MDM

\section{$5 \quad$ Conclusion and Future Research}

The proposed concept of complexity management in production systems provides the opportunity for problem solvers to use structural consideration in complex situations to gain more relevant information and thereby to optimize solutions. Particularly in times of strong change and many internal and external influencing factors, it is becoming increasingly important to securely capture, understand and use those situations.

The presented framework provides the basis for a holistic approach to complexity management. It contains human, technical and organizational aspects to model required system sections, to analyze these models as well as to integrate the concept in a production environment. Following points has been worked out for further research and improvement of the proposed concept:

- Industrial survey on relevant domains and validation of concepts (relevance cycle in DSR)

- Research on technical implementation, such as expert systems and artificial intelligence

- Possibilities of data collection and validation, followed by industrial application 


\section{References}

1. Schenk, M., Wirth, S., Müller, E.: Factory Planning Manual. Situation-Driven Production Facility Planning. Springer-Verlag Berlin Heidelberg, Berlin, Heidelberg (2010)

2. Vogel-Heuser, B., Bauernhansl, T., Hompel, M.t. (eds.): Handbuch Industrie 4.0 Bd.4: Allgemeine Grundlagen, 2nd edn. Spinger-Verlag GmbH Deutschland (2017)

3. Horler, S., Müller, E.: Strukturplanung zukünftiger Produktionssysteme. Industrie 4.0 Management (3), pp. 47-55. (2017)

4. Grübner, A.: Bewältigung marktinduzierter Komplexität in der industriellen Fertigung. Europäische Hochschulschriften. Reihe 5, Volks- und Betriebswirtschaft Publications v. 3244. P. Lang, Frankfurt am Main, New York (2007)

5. Dresch, A., Lacerda, D.P., Antunes Jr, José Antônio Valle: Design Science Research. A Method for Science and Technology Advancement. Springer Publishing, Cham (2015)

6. Wiener, N.: Cybernetics or control and communication in the animal and the machine. second edition. MIT Press (1961)

7. Bertalanfy, L. von: An Outline of General System Theorie. In: British Journal for the Philosophy of Science 1, vol. 2, pp. 134-165 (1950)

8. Hall, A.D.: A Methodology for Systems Engineering. Van Nostrand (1962)

9. Beer, S.: Brain of the firm. The managerial cybernetics of organization, 2nd edn. The managerial cybernetics of organization. Wiley, Chichester u.a. (1995)

10. Ulrich, H., Probst, Gilbert J. B: Anleitung zum ganzheitlichen Denken und Handeln. Ein Brevier für Führungskräfte, 4th edn. Haupt, Bern (1995)

11. Bleicher, K.: Das Konzept Integriertes Management, 7th edn. Campus Verlag, Frankfurt am Main (2004)

12. Gomez, P., Malik, F., Oeller, K.-H.: Systemmethodik. Grundlagen einer Methodik zur Erforschung und Gestaltung komplexer soziotechnischer Systeme. Diss. Hochschule St. Gallen: Schriftenreihe Betriebswirtschaft, vol. 4. Haupt, Bern u.a. (1975)

13. Fricker, A.R.: Eine Methodik zur Modellierung, Analyse und Gestaltung komplexer Produktionsstrukturen. Dissertation, Aachen (1996)

14. Malik, F.: Strategie des Managements komplexer Systeme. Ein Beitrag zur ManagementKybernetik evolutionärer Systeme, 11th edn. Haupt, Bern (2015)

15. Lindemann, U., Maurer, M., Braun, T.: Structural complexity management. An approach for the field of product design. Springer, Berlin (2009)

16. Kreimeyer, M., Lindemann, U.: Complexity Metrics in Engineering Design. Managing the Structure of Design Processes. Springer Verlag Berlin/Heidelberg (2011)

17. Petraus, B., Arnold, R., Riedel, R., Müller, E.: Matrices-based modeling of communication within planning projects. IEEE International Conference on Industrial Engineering and Engineering Management (2013)

18. Nyhuis, P., Reinhart, G., Abele, E. (eds.): Wandlungsfähige Produktionssysteme. Heute die Industrie von morgen gestalten. PZH Produktionstechnisches Zentrum, Hannover (2008)

19. Schmigalla, H.: Fabrikplanung. Begriffe und Zusammenhänge, 1st edn. REFAFachbuchreihe Betriebsorganisation. Hanser, München, Wien (1995)

20. Riedel, R.: Sytemische Fabrikbetriebsplanung auf Basis eines kybernetisch-soziotechnischen Modells. Habilitationsschrift (2012)

21. Ashby, W.R.: An Introduction to Cybernetics. Chapman \& Hall Ltd., London (1970)

22. Ropohl, G.: Allgemeine Technologie. Eine Systemtheorie der Technik, 3rd edn. Universitätsverlag Karlsruhe, Karlsruhe (2009)

23. Bartolomei, J.E.: Qualitative Knowledge Construction for Engineering Systems: Extending the Design Structure Matrix Methodology in Scope and Procedure (2007) 